\title{
PERCEPTION OF PITCH CHANGES IN HEARING-IMPAIRED ADULTS WITH AIDED AND UNAIDED HEARING LOSS
}

\author{
Karen Schauwers ${ }^{1}$, Martine Coene ${ }^{2}$, Willemijn Heeren ${ }^{3}$, Luca Del Bo ${ }^{4}$, Alexandru Pascu 5 , \\ Bart Vaerenberg ${ }^{1,6}$, Paul J. Govaerts ${ }^{1}$
}

\author{
${ }^{1}$ The Eargroup, Antwerp-Deurne, Belgium \\ ${ }^{2}$ VU Free University Amsterdam, Amsterdam, The Netherlands \\ ${ }^{3}$ Leiden University, Leiden, The Netherlands \\ ${ }^{4}$ Fondazione Ascolta e Vivi, Milan, Italy \\ ${ }^{5}$ Bucharest University, Bucharest, Romania \\ ${ }^{6}$ Laboratory of Biomedical Physics, University of Antwerp, Antwerp, Belgium
}

Corresponding author: Paul J. Govaerts, The Eargroup, Herentalsebaan 75, 2100 Deurne, Belgium, e-mail: dr.govaerts@eargroup.net

\begin{abstract}
Background: Pitch relates to the low frequency temporal content of sound, which mainly depends on phase coding at the level of the auditory nerve. In this study, we aim to assess the detectibility of pitch changes in different populations of hearingimpaired subjects suffering from sensorineural hearing loss in order to identify possible poor temporal coding.

Material and Methods: A number of tests - part of the A§E (ASSE or Auditory Speech Sounds Evaluation) psychoacoustic test suite - were used to assess the perception of pitch changes in adults with a hearing loss (a) in the high frequencies with or without classical hearing aids, (b) in the low frequencies, and (c) in a group of cochlear implant users. All test stimuli were controlled for their fundamental frequency (F0), which either remained stable during the stimulus presentation or which, simulating intonation, glided from $\mathrm{F} 0$ to $\mathrm{F} 0+\Delta$. Isolated synthetic complexes were used as well as pseudo-words or pseudosentences mimicking linguistically relevant contexts. The subjects were asked to distinguish these sounds in either identification or discrimination tasks.
\end{abstract}

Results: Hearing-impaired subjects, and particularly those with low-frequency hearing loss, performed significantly worse in comparison to hearing adults on all tests. The use of a hearing aid did not yield significant improvements. The cochlear implant users experienced great difficulty in performing the tests.

Conclusion: The intonation tests of A\$E2009 are a useful diagnostic tool to distinguish hearing-impaired subjects based on their capacity to process low-frequency information. The tests may be of particular use in the evaluation of the impact of auditory rehabilitation, hearing aids, or electro-acoustic stimulation.

Key words: pitch perception • sensorineural hearing loss • cochlear implants

\section{PERCEPCIÓN DE CAMBIOS DE TONO EN ADULTOS CON DIFICULTADES AUDITIVAS CON PÉRDIDA DE AUDICIÓN CON Y SIN AUDÍFONOS}

\section{Extracto}

Antecedentes: El tono se refiere al contenido de baja frecuencia temporal de sonido, que depende principalmente de la fase de codificación a nivel del nervio auditivo. En este estudio, hemos intentado determinar la detectabilidad de los cambios de tono en diferentes poblaciones de pacientes con problemas de audición que padecen de pérdida auditiva neurosensorial, con el fin de identificar posible mal codificación temporal.

Material y Métodos: Se utilizaron una serie de pruebas - parte del conjunto de pruebas psicoacústicas A@E (ASSE o Evaluación Auditiva de Sonidos del Habla) - para evaluar la percepción de los cambios de tono en adultos con pérdida auditiva (a) en las frecuencias altas con o sin audífonos clásicos, (b) en las frecuencias bajas, y (c) en un grupo de usuarios de implantes cocleares. Todos los estímulos de prueba fueron controlados en cuanto a su frecuencia fundamental (F0), que, o bien se mantuvo estable durante la presentación del estímulo o, simulando entonación, se deslizó de F0 a F0 $+\Delta$. Se utilizaron aislados complejos sintéticos, así como pseudo-palabras o pseudo-sentencias imitando contextos lingüísticamente pertinentes. A los sujetos se les pidió que distinguieran estos sonidos, ya sea en las tareas de identificación o discriminación.

Resultados: Los resultados de pacientes con problemas auditivos, y en particular aquellos con pérdida auditiva de baja frecuencia, fueron significativamente peores en comparación con los adultos sin deficiencias auditivas en todas las pruebas. El uso de 
un audífono no produjo mejoras significativas. Los usuarios de implantes cocleares experimentaron grandes dificultades en la realización de las pruebas.

Conclusión: Las pruebas de entonación de A§E2009 son una herramienta de diagnóstico útil para distinguir los pacientes con discapacidad auditiva en función de su capacidad para procesar información de baja frecuencia. Las pruebas pueden ser particularmente útiles en la evaluación del impacto de la rehabilitación auditiva, audífonos, o la estimulación electro-acústica.

Palabras claves: la precepción del tono • la pérdida auditiva neurosensorial • implantes cocleares

\section{ВОСПРИЯТИЕ ИЗМЕНЕНИЙ ВЫСОТЫ ЗВУКА У ВЗРОСЛЫХ С НАРУШЕНИЯМИ СЛУХА, ПОТЕРЕЙ СЛУХА СО СЛУХОВЫМИ АППАРАТАМИ И БЕЗ СЛУХОВЫХ АППАРАТОВ}

\section{Резюме}

Предпосылки: Высота звука относится к низкочастотному временному объему звука, которая в основном зависит от кодирования фазы на уровне слухового нерва. Цель нашей исследовательской работы - оценить выявляемость изменений высоты тона в различных группах людей с нарушениями слуха, страдающих сенсонейронной потерей слуха, чтобы определить возможное низкое временное кодирование.

Материалы и Методы: Несколько тестов - часть A§E (ASSE или Оценка Речевых Звуков) набор психоакустических тестов, в которых оценивалось восприятие изменеий высоты тона у взрослых с потерей слуха (а) на высоких частотах с или без классических вспомогающих слуховых устройств, (б) на низких частотах и (в) в группе пользователей кохлеарных слуховых имплантов. Во всех тестовых стимулах контролировалась основная частота (F0), которая либо оставалась стабильной во время презентации стимула, либо, имитируя интонацию, постепенно переходила от F0 до F0+ $\Delta$. Использовались как отдельные синтетические совокупности, так и псевдо-слова или псевдо-предложения, имитирующие лингвистически соответственные контексты. Тестированных людей попросили определить эти звуки в заданиях отождествления и распознавания.

Результаты: Люди с нарушениями слуха, в особенности лица с низкочастотной потерей слуха, выполнили все тесты гораздо хуже по сравнению со слышащими. Использование слуховых аппаратов не принесло значительного улучшения. Пользователи кохлеарных имплантов имели большие проблемы с выполнением этих тестов.

Заключение: тесты интонации A§E2009 это полезные диагностические инструменты для выявления нарушений слуха, основанные на способности обрабатывать низкочастотную информацию. Эти тесты могут быть особенно полезны для оценки воздействия слуховой реабилитации, слуховых аппаратов или электроакустической стимуляции.

Ключевые слова: восприятие высоты звука, сенсонейронная потеря слуха, кохлеарные импланты

\section{Background}

Sound can be described by three features: amplitude, spectral content, and temporal content. The coding of these features by the cochlea is based on different underlying physiological mechanisms, including tonotopy in the case of spectral content coding $[1,2]$. Temporal content can be divided into fluctuations in the sound envelope (the relatively slow variations in amplitude over time) and fluctuations in the temporal fine structure (TFS). Whereas the envelope coding can be explained by means of intensity coding and tonotopy, the coding of TFS requires the additional mechanism of phase locking [3]. This is an electrophysiological mechanism in which hair cells are activated at the same frequency as that of the incoming sound. Both envelope cues and TFS cues seem to convey segmental and suprasegmental or prosodic cues in speech. However, it is generally thought that envelope cues code information about manner, tempo, rhythm, and syllabicity in speech, while TFS cues play a role in the encoding of pitch, place, voicing, and voice quality $[4,5]$. From a psycho-acoustic point of view, the place coding mechanism is thought to be involved in resolving the higher frequencies, including formant frequencies and harmonics, whereas the temporal coding mechanism is especially involved in resolving the lower frequencies, including the fundamental frequen$\mathrm{cy}$, since it has been shown that neural phase locking decreases from about $1 \mathrm{kHz}$ and completely breaks down for frequencies above $4-5 \mathrm{kHz}$ in most mammals [6-8].

Several researchers have investigated the role of place cues and temporal cues in speech identification tasks in quiet. With regard to place cues, the results show that speech intelligibility in quiet is barely affected by a diminished place coding ability (as is the case for an impaired auditory system with broader-than-normal cochlear filters) [9]. The same is true for envelope and TFS cues. By using signal processing techniques which preserve envelope cues while removing TFS cues or vice versa, it has been shown that envelope cues can yield high levels of identification for speech 
presented in quiet [10]. This is also the case for TFS-speech, provided that listeners are trained for a few hours $[11,12]$.

Over the last several decades, many studies have compared speech identification in steady state and fluctuating noise in an attempt to find out what role spectral and temporal cues play. These studies have demonstrated that, for normal hearing listeners, speech identification performance was better in fluctuating noise than in steady state noise, which is known as "masking release": normal hearing listeners are able to "glimpse" speech in background noise valleys (a capacity also called "dip listening"). Baer and Moore $[9,13]$ found that place cues are important for listening to speech in the presence of steady state noise and interfering speech sounds, especially in the spectral dips. However, place cues and envelope cues are not sufficient to achieve normal speech intelligibility in fluctuating backgrounds. It has been suggested that the normal auditory system can decide, by using information derived from neural phase locking to TFS [3], whether a speech signal in the dips of a background sound is produced by the target speech, or whether it is part of the background sound. Indeed, it has been shown that TFS cues strongly diminish masking release [14-19].

Cochlear damage has a large effect on place coding. Reduced frequency selectivity means that hearing-impaired listeners do not have access to the fine details of a sound's spectral profile, such as spectral peaks and troughs in target and masking speech. It also means that hearing-impaired listeners are more susceptible to masking across frequencies, which partially explains why they perform poorly when listening in noise $[9,13]$. Similarly, cochlear damage degrades the ability to encode and use TFS cues $[12,20,21]$, which leads to a reduced ability to make use of masking release for understanding speech in noise $[22,23]$. Even normal audiometric thresholds at low frequencies can be associated with strong abnormalities in the processing of TFS cues in speech at those frequencies $[24,25]$. In contrast, cochlear damage seems to preserve the ability to use envelope cues [26-28]. Besides individuals with high frequency sensorineural hearing loss, patients with low frequency loss, as seen in Menière's disease, are expected to experience particular difficulties with the perception of TFS cues. Menière's disease is a disorder of the cochlea which affects balance (including episodes of vertigo) and which is typically associated with a hearing loss in the lower frequency range $(125-1000 \mathrm{~Hz})$, often combined with episodes of tinnitus. It has been claimed that Menière's disease is associated with abnormal firing in the auditory nerve and that this results in a decreased ability to make use of TFS cues. Patients with Menière's disease are known to experience severe difficulties in understanding speech in noise and in spatially separating voices [29].

It is known that in many languages prosody or pitch contributes to the processing of semantics, syntax, discourse structure, clause typing, and paralinguistic information [30-34]. Linguistically relevant constructions, including sentence intonation and lexical stress, are cued by lowfrequency information. In fact, the most important acoustic correlate of prosody is the fundamental frequency, and accent (lexical stress) is often expressed by changes in the fundamental frequency.
A better insight into the coding of low frequencies may also relate to therapeutic strategies for hearing-impaired individuals. Depending on the type and degree of a patient's hearing loss, current interventions include digital hearing aids (HAs) or cochlear implants (CIs). Cochlear implant devices focus at replacing the place coding. However, they remain unable to convey TFS information at low frequencies $[16,35]$. As a consequence, CI users are provided with only very restricted information about pitch. Newer developments such as electro-acoustic stimulation (EAS) may result in better coding of low frequencies and therefore may improve pitch and music perception in CI users.

To date, only a few studies have investigated low frequency coding in hearing-impaired individuals in unaided as well as aided (with conventional HAs or CIs) conditions $[12,36,37]$. Recently, a number of A\$E modules (ASSE, or Auditory Speech Sounds Evaluation [38]) were developed by a European consortium consisting of companies and universities of Belgium, the Netherlands, Italy, and Romania (FP7-SME1-2007-grant \#222291, "DUAL PRO" [39]) which aims at the clinical assessment of low frequency coding. In this paper, we report on the prosodic perception skills of these different hearing-impaired populations, in relation to their high or low frequency loss and the possible use of a classical HA or CI.

\section{Material and Methods}

\section{Participants}

Three groups of hearing-impaired adults were selected based on the following criteria:

1. high frequency hearing loss (hereafter "HI HF"), meaning a presbyacusis-like hearing loss with thresholds of $\leq 30 \mathrm{dBHL}$ at 250 and $500 \mathrm{~Hz}$ and thresholds of $\geq 40$ $\mathrm{dBHL}$ from $2 \mathrm{kHz}$ onwards in the better ear. A total of 82 HI HF subjects were included, 30 each from Dutch and Romanian language backgrounds and 22 from an Italian language background. Figure 1 shows the mean audiograms $(+\mathrm{SD})$ for the right ear and left ear.

2. low frequency hearing loss (hereafter "HI LF"), meaning a Menières-like hearing loss with thresholds of $\geq 35$ $\mathrm{dBHL}$ at $500 \mathrm{~Hz}$ and thresholds at 2 and $4 \mathrm{kHz}$ which were not worse than the threshold at $500 \mathrm{~Hz}$ in the better ear. Data from $30 \mathrm{HI}$ LF subjects were obtained, including 10 from each of the three language backgrounds. Since these subjects were not used to wearing hearing aids, they were only tested in the unaided condition. The mean audiogram $(+\mathrm{SD})$ of the better ear is shown in Figure 2.

3. a group of cochlear implant users (hereafter "CI") with an unaided profound hearing loss of $\geq 85 \mathrm{dBHL}$ on all tested frequencies ranging from 125 to $8000 \mathrm{~Hz}$. This group consists of 21 postlingual subjects wearing a cochlear implant unilaterally, including 9 Dutch, 6 Romanian, and 6 Italian subjects, and 4 device types (Nucleus Freedom $(n=8)$, Advanced Bionics Harmony $(n=4)$, Med-El Opus $(n=7)$, and Neurelec SP $(n=2))$.

In addition, data were collected from a control group consisting of 90 hearing adults, 30 per language background (Dutch, Romanian, and Italian). These subjects were selected based on the following criteria: (i) hearing 

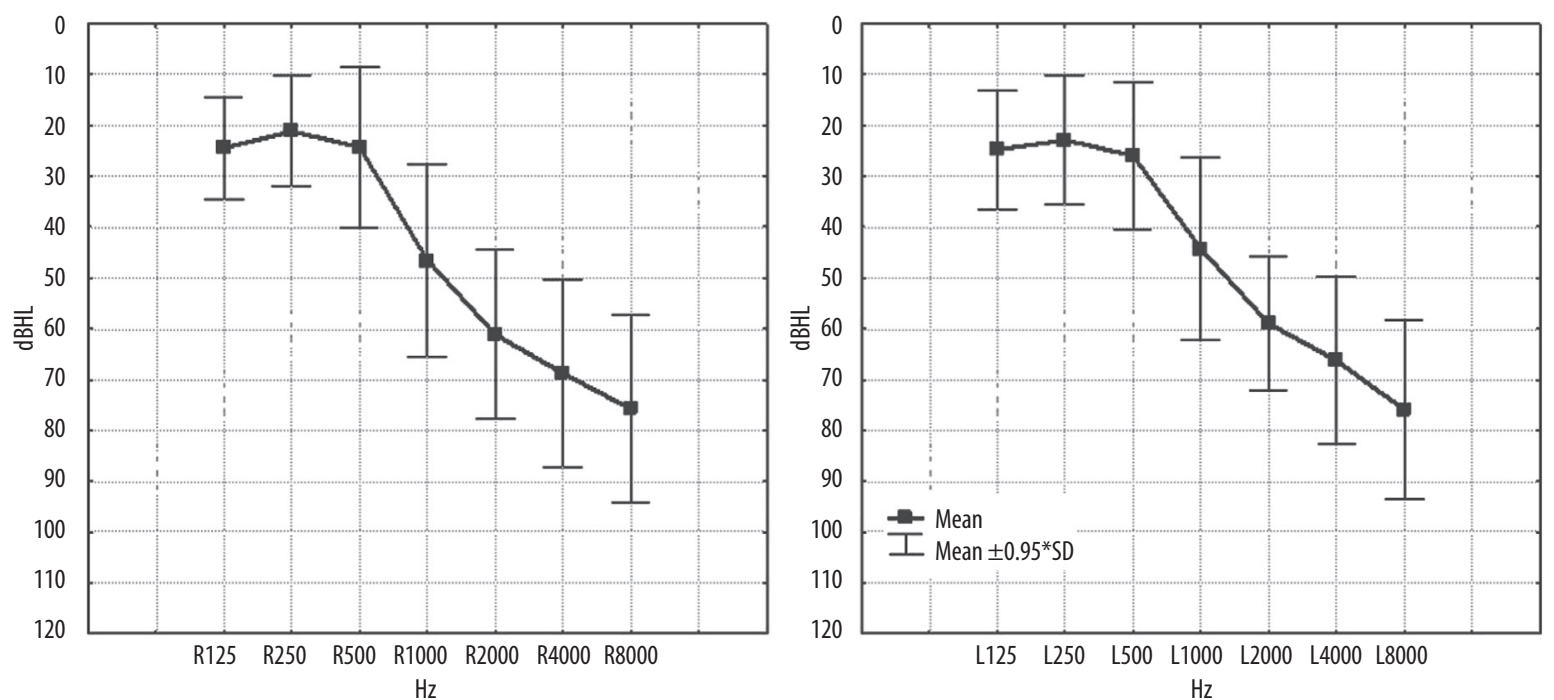

Figure 1. Mean audiogram (and SD) for the right ear (left panel) and the left ear (right panel) in the HI HF group ( $n=82$ ).

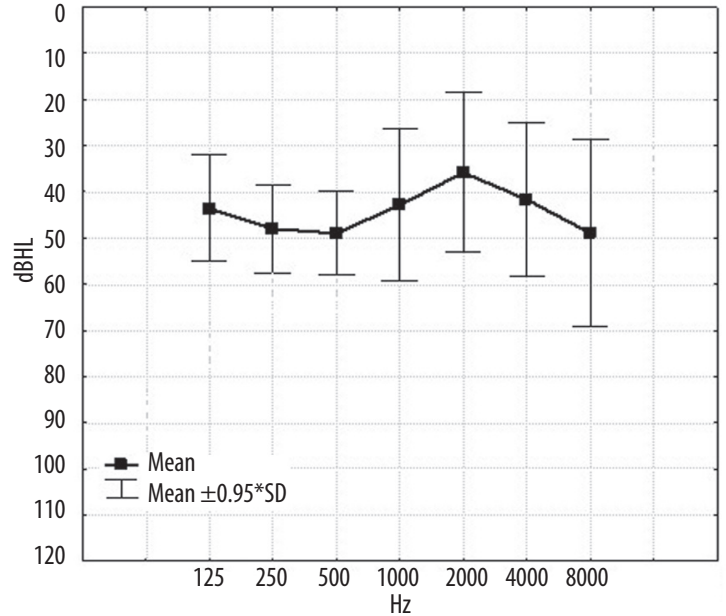

Figure 2. Mean audiogram (and SD) for the better ear in the HI LF group ( $n=30)$.

thresholds of $<20 \mathrm{dBHL}$ at frequencies between 125 and $8000 \mathrm{~Hz}$ for both ears; (ii) no history of ear problems or ear surgery.

\section{A§E 2009 prosodic test battery}

A detailed description of the development of the A $\$ \mathrm{E}$ prosodic tests can be found elsewhere [39,40]. Briefly, the A\$E prosodic test battery consists of three intonation tests: 1) the Harmonic Intonation (HI) and Disharmonic Intonation (DI) test; 2) the Sentence Intonation (SI) test; and 3) the Word Stress Pattern (WSP) test. The features of these tests are listed in Table 1. The test task for HI/DI and SI is a same-different discrimination task in which two stimuli are presented consecutively (with an inter-stimulus interval of $500 \mathrm{~ms}$ ), one of which has intonation while the other does not. The test task for WSP is an identification task. The stimuli used in the tests are either purely synthetic (HI/DI) or pseudo-linguistic, mimicking sentences (SI) or words (WSP). Each of the tests has one variant in which high-frequency cues are still available and a variant in which those high-frequency cues are removed, either synthetically (DI) or by low-pass filtering (SI LPF and WSP LPF). In the latter case, each word and sentence stimulus was low-pass filtered (MATLAB Filter function: $300 \mathrm{~Hz}$ cut-off frequency, $90 \mathrm{~dB}$ attenuation in magnitude over a $50 \mathrm{~Hz}$ transition width) and high-pass filtered white noise added $(250 \mathrm{~Hz}$ cut-off frequency, $85 \mathrm{~dB}$ gain in magnitude over a $50 \mathrm{~Hz}$ transition width).

In the HI/DI tests, the non-intonating stimulus is a harmonic tone complex with a fundamental frequency (F0) of $200 \mathrm{~Hz}$ and three higher harmonics with frequencies of $2 \mathrm{~F} 0,3 \mathrm{~F} 0$, and $4 \mathrm{~F} 0$. The intensity of each harmonic is $6 \mathrm{~dB}$ lower than the former component. White noise was added to the stimuli $(\mathrm{SNR}+10.9 \mathrm{~dB})$ to make them sound more natural. In both the HI and DI tests, this non-intonating stimulus is presented in contrast to an intonating stimulus. The intonating sounds used in the $\mathrm{HI}$ test feature a frequency sweep of all harmonics (including F0) from NF0 to $\mathrm{N}(\mathrm{F} 0+\Delta \mathrm{F})$, with $\mathrm{N}$ ranging from 1 to 4 . In the DI test, the intonating sounds feature a sweep of F0 only (from F0 to $\mathrm{F} 0+\Delta \mathrm{F}$ ), while the higher harmonics are kept fixed at their initial frequency. This causes the perception of disharmony or dissonance. The $\Delta \mathrm{F} 0$ ranges from 0 to $214 \mathrm{~Hz}$ (so in the case of a $\Delta \mathrm{F} 0$ of $0 \mathrm{~Hz}$, there is no difference between the two stimuli presented).

In the SI test and its low-pass filtered variant (SI LPF), the pseudo-sentences are constructed based on an inventory of over 30,000 Dutch, Italian, and Romanian syllables consisting of frequently occurring (sonorant) phonemes (i.e. the consonants $/ \mathrm{m} /$ and $/ \mathrm{n} /$ and the vowels $/ \mathrm{a} /$, $/ \mathrm{i} /$, and $/ \mathrm{u} /$ ). Four to six of these syllables are concatenated to simulate a sentence. A fixed accent is imposed on the second syllable to mimic a typical sentence-like structure. A rise of F0 was imposed on the last syllable to address the perception of clause typing. This $\Delta \mathrm{F} 0$ is variable (as shown in Figure 3A). In the test, the non-intonating stimulus is a pseudo-sentence with a flat ending $(\Delta \mathrm{F} 0$ is 0 $\mathrm{Hz}$ ) and the intonating stimuli are pseudo-sentences with a $\Delta \mathrm{F} 0$ between 0 and $208 \mathrm{~Hz}$. 
Table 1. Features of the three A§E intonation tests.

\begin{tabular}{cccc}
\hline & HI/DI & SI & WSP \\
\hline Test task & discrimination & discrimination & identification \\
\hline Stimuli & synthetic & pseudo-sentences & pseudo-words \\
\hline Linguistic context & no & yes & yes \\
\hline Low Freq mode & DI & low-pass filtering & low-pass filtering \\
\hline
\end{tabular}

A

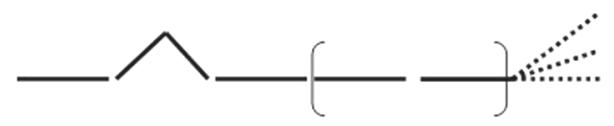

B

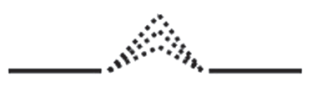

Figure 3. Model of the sentence pitch contour (A), and the word pitch contour (B) illustrated through movement on the second syllable.
The WSP test and its low-pass filtered variant (WSP LPF) is a closed-set identification task using pseudo-words of three syllables. These pseudo-words are constructed with syllables containing the same frequently occurring sonorant consonants and vowels as those of the SI test. On one of the three syllables a pitch accent is imposed, mimicking lexical stress. This pitch accent consists of a rise of F0 followed by a reversal to its original value of $200 \mathrm{~Hz}$. A word pitch contour with movement on the second syllable is illustrated in Figure 3B. The listener's task is to indicate which of the three syllables of the nonsense word carries a pitch accent or whether there is no noticeable accent at all. The $\Delta \mathrm{F} 0$ ranges from 0 to $208 \mathrm{~Hz}$.

All tests are designed to find the just noticeable difference (JND, also called difference limen or threshold) for pitch discrimination using an adaptive staircase procedure [41] which estimates the $50 \%$ point on a participant's psychometric function. Both stochastic processes and internal controls are used to determine the exact number of reversals needed for good threshold estimation per listener, which was preferred over the use of a fixed number of reversals.

It must be kept in mind that whereas these tests aim at assessing pitch perception, high JNDs may be biased by acoustic artifacts which generate temporal cues like beating. As explained in a previous paper [40], temporal modulation transfer functions are known to be low pass with a cutoff frequency near 70 bps for normal hearing listeners. This means that such artifacts come into play with pitch glides from $200 \mathrm{~Hz}$ to $330 \mathrm{~Hz}$ or higher. Therefore we believe that although the test algorithm goes as high as 214 or $208 \mathrm{~Hz}$, high JNDs (of $130 \mathrm{~Hz}$ or more) should be interpreted with caution.

\section{Test procedure}

All participants were tested according to the same protocol (in their respective native language: Dutch, Romanian, or Italian). They were seated in a soundproof booth facing a loudspeaker. The HI LF group was tested under headphones (only the better ear, see criterion above), the others in free field condition, both in the unaided and the aided condition. Device settings were not modified for the test procedure. The tester was seated outside the booth. All test items were presented at $70 \mathrm{~dB}$ SPL. Intensity roving
( $\pm 3 \mathrm{~dB}$ ) was applied to de-condition the subject to use loudness as a cue for discrimination. The test order varied per subject, thus minimising effects of learning or habituation across listeners. For all discrimination tasks (HI, DI, SI, and SI LPF), the subjects were instructed to indicate whether they detected a difference between the two stimuli or not. For the WSP and WSP LPF tests, the instruction was to indicate on which of three syllables a pitch accent was perceived or to indicate that no accent was perceived.

Each of the tests started with a training mode in order to familiarise the subjects with the test procedure and the stimuli. The training time was restricted to 10 minutes. During the test phase, the stimuli were presented automatically following the adaptive staircase algorithm of $\mathrm{A} \S \mathrm{E}$, seeking the JND $(\Delta \mathrm{Hz})$.

\section{Analysis}

Per test and per subject, a JND was obtained in Hz. In case no JND could be found within 100 trials, the JND was set to $220 \mathrm{~Hz}$ (i.e. above the maximum $\Delta \mathrm{F}$ value of $208 \mathrm{~Hz}$ for the linguistic tests and $214 \mathrm{~Hz}$ for the synthetic sounds tests). All results were analysed using non-parametric descriptive statistics (Tukey with box-and-whisker plots) and non-parametric analysis statistics (Kruskal-Wallis test, Mann-Whitney U-test, and Wilcoxon matched pairs test) with a cut-off level of 0.05 .

\section{Results}

\section{Unaided hearing-impaired subjects}

Figure 4 shows the JND values for the hearing controls and the two groups of unaided hearing-impaired subjects (HI HF and HI LF), displayed as box-and-whisker plots, for the three intonation tests (HI, SI, and WSP), together with their low-pass filtered variant (DI, SI LPF, WSP LPF). Statistical analysis (Kruskal-Wallis test) showed that both the HI HF group and the HI LF group reached significantly higher JNDs (and thus worse results) than the hearing controls on all tests $(p<0.01$ for WSP in the HI HF $-\mathrm{NH}$ comparison; $p<0.001$ for all other comparisons). The HI LF group performed significantly worse than the HI HF group on all tests $(p<0.05$ for WSP; $p<0.01$ for WSP LPF; $p<0.001$ for the remaining tests). 


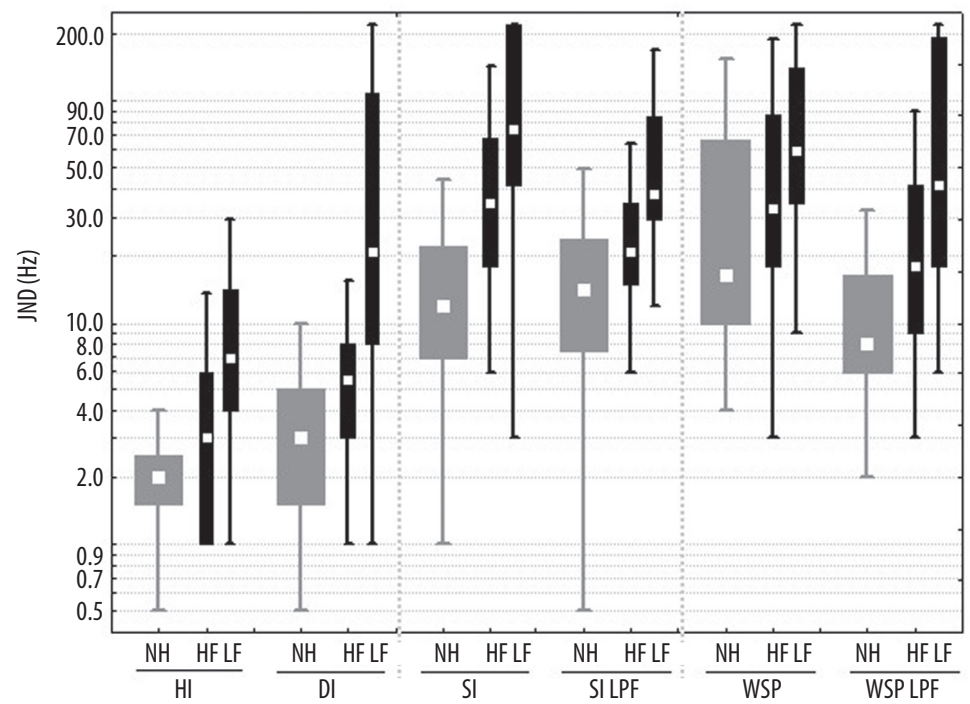

Figure 4. JNDs in $\mathrm{Hz}$ for the three subject groups $\mathrm{NH}, \mathrm{HI} \mathrm{HF}$, and $\mathrm{HI} \mathrm{LF}$ on a logarithmic scale for the Harmonic Intonation test ( $\mathrm{HI})$, the Disharmonic Intonation test (DI), the Sentence Intonation test (SI) and its low-pass filtered variant (SI LPF), and the Word Stress Pattern test (WSP) and its low-pass filtered variant (WSP LPF). The box and whisker plots show the median (central dot), quartile range (box: from lower to upper quartile), and range (whiskers: from lower to upper extreme).

Table 2. Median JNDs ( $\mathrm{Hz})$ in the unaided and aided condition for the HI HF group.

\begin{tabular}{ccccccc}
\hline & HI & DI & SI & SI LPF & WSP & WSP LPF \\
\hline Unaided & 3 & 5.5 & 34.5 & 21 & 32.8 & 18 \\
\hline Aided & 3 & 5.0 & 27.5 & 21 & 25.8 & 15 \\
\hline
\end{tabular}

The results showed that for all groups the JNDs for the synthetic sounds tests (HI and DI) were significantly lower than for the linguistic tests (SI, SI LPF, WSP, and WSP LPF) (NH: $Z=7.9, p<0.001$; HI HF: $Z=7.1, p<0.001$; HI LF: $Z=4.7, p<0.001)$.

The effect of filtering was investigated by performing the Wilcoxon matched pairs test. In case of the linguistic tests, these analyses showed that the JNDs for the filtered SI test were significantly lower than for the unfiltered SI test in the two HI groups (HI HF: $Z=4.9, p<0.001$; HI LF: $Z=3.0, p<0.01$ ), but not in the hearing control group (NH: $Z=0.3, p>0.05$ ). The same trend was seen for the two versions of the WSP test (NH: $Z=4.5, \mathrm{p}<0.001$; HI HF: $Z=3.5, p<0.001$ ), although not statistically significant for the HI LF group $(Z=1.4, p>0.05)$. In contrast, for the synthetic tests, all subject groups demonstrated significantly lower JND values for the unfiltered $\mathrm{HI}$ test in comparison to the filtered DI test $(\mathrm{NH}: Z=5.2$, $p<0.001$; HI HF: $Z=3.9, p<0.001$; HI LF: $Z=4.2, p<0.001)$.

\section{Aided hearing-impaired subjects}

In the HI HF group, we did not find statistically significant improvements in JNDs when tested with hearing aids in comparison to the unaided condition for any of the seven intonation tests (Wilcoxon matched pairs test). The median JNDs for the unaided and aided conditions are shown in Table 2.

Figure 5 shows the JND values for the CI group in comparison to our control group of hearing adults. The results show that CI subjects had much more difficulty attaining low JNDs, especially for the low-frequency DI test and all linguistic tests. We found statistically significant differences between the two groups for all tests using the Mann-Whitney U-test (HI: $Z=-6.4, p<0.001$; DI: $Z=-5.9, p<0.001$; SI: $Z=-6.0, p<0.001$; SI LPF: $Z=-5.5, p<0.001$; WSP: $Z=-6.0$, $p<0.001$; WSP LPF: $Z=-5.1, p<0.001)$. However, the variability within the CI group was quite large, indicating that some $\mathrm{CI}$ subjects were able to perform within the normal range.

Similar to the hearing-impaired groups and the hearing controls, the median JNDs for the synthetic tests in the CI group were significantly lower than those for the linguistic tests (Wilcoxon matched pairs test: $Z=3.7, p<0.001$ ), mainly because of the relatively good scores on the HI test.

Although the CI subjects demonstrated the same trend of improved JNDs when filtering the SI and WSP tests, the differences in scores between the filtered and unfiltered tests were not statistically significant according to the Wilcoxon matched pairs test (SI-SI LPF: $Z=0.2, p>0.05$; WSP-WSP LPF: $Z=1.9, p>0.05)$. Similar to the NH and HI groups, the effect of filtering seemed to be reversed for the synthetic tests: CI subjects showed significantly lower JNDs for the unfiltered HI test than for the filtered variant (DI) $(Z=3.4, p<0.001)$.

Table 3 shows the individual JND results of the CI subjects, classified according to the type of implant.

\section{Discussion}

It is common practice in clinical audiological assessment to perform pure tone audiometry to determine hearing threshold, and use speech audiometry as a supraliminal test to have an idea about speech understanding. However, it is our belief that other tests are required to allow a 


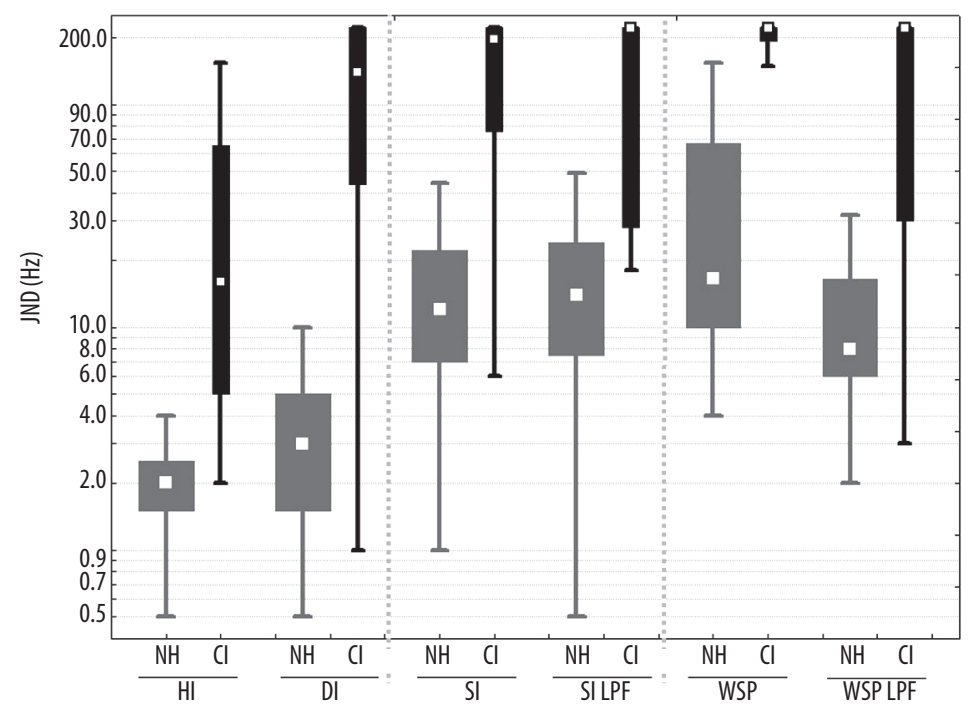

Figure 5. JNDs in $\mathrm{Hz}$ for the $\mathrm{NH}$ and $\mathrm{Cl}$ subjects on a logarithmic scale for the Harmonic Intonation test $(\mathrm{HI})$, the Disharmonic Intonation test (DI), the Sentence Intonation test (SI) and its low-pass filtered variant (SI LPF), and the Word Stress Pattern test (WSP) and its low-pass filtered variant (WSP LPF). Box and whisker plots as per Figure 4.

Table 3. Individual JND results $(\mathrm{Hz})$ of the $\mathrm{Cl}$ group.

\begin{tabular}{|c|c|c|c|c|c|c|c|}
\hline Cl type* & Language & HI & DI & SI & SI LPF & WSP & WSP LPF \\
\hline Harmony & Dutch & 41 & 220 & 220 & 220 & 220 & 220 \\
\hline Harmony & Dutch & 94 & 220 & 100 & 220 & 150 & 220 \\
\hline Harmony & Dutch & 6 & 203 & 52 & 220 & 220 & 220 \\
\hline Harmony & Dutch & 10 & 139 & 220 & 220 & 220 & 3 \\
\hline Freedom & Dutch & 70 & 220 & 220 & 220 & 220 & 220 \\
\hline Freedom & Dutch & 192 & 114 & 220 & 220 & 220 & 220 \\
\hline Freedom & Dutch & 3 & 114 & 197 & 220 & 220 & 15 \\
\hline Freedom & Italian & 120 & 120 & 220 & 18 & 220 & 220 \\
\hline Freedom & Italian & 59 & 220 & 150 & 220 & 111 & 220 \\
\hline Freedom & Italian & 4 & 220 & 220 & 220 & 220 & 220 \\
\hline Freedom & Italian & 21 & 98.5 & 220 & 220 & 220 & 220 \\
\hline Freedom & Italian & 18 & 29 & 220 & 52 & 220 & 21 \\
\hline Opus & Romanian & 16 & 59 & 128.5 & 220 & 220 & 220 \\
\hline Opus & Romanian & 5 & 1 & 6 & 18 & 34.5 & 21 \\
\hline Opus & Romanian & 2 & 23 & 52 & 24 & 186 & 38 \\
\hline Opus & Romanian & 9 & 22 & 34.5 & 18 & 197 & 135 \\
\hline Opus & Romanian & 12 & 220 & 111 & 31 & 220 & 52 \\
\hline Opus & Romanian & 3 & 2 & 31 & 18 & 38 & 6 \\
\hline Opus & Italian & 220 & 220 & 220 & 220 & 220 & 220 \\
\hline Digi SP & Dutch & 5 & 220 & 220 & 220 & 220 & 220 \\
\hline Digi SP & Dutch & 34 & 220 & 150 & 220 & 220 & 220 \\
\hline Q25 & & 5 & 44 & 76 & 28 & 192 & 30 \\
\hline Median & & 16 & 139 & 197 & 220 & 220 & 220 \\
\hline Q75 & & 65 & 220 & 220 & 220 & 220 & 220 \\
\hline
\end{tabular}

* "Harmony" - Advanced Bionics; "Freedom"- Cochlear; "Opus" - Med-El; "Digi SP" - Neurelec.

() Journal of Hearing Science ${ }^{\oplus} \cdot 2012$ Vol. 2 . No. 3 
more fine-grained analysis of cochlear functioning and to improve the diagnostic power of sensorineural hearing loss. With the development of new treatments for cochlear deficits - including more advanced and specific drug therapies, enhanced genetic insights into cochlear deficits, and advanced technical solutions for cochlear hearing losses such tests can improve the assessment of cochlear functioning before and after therapy. The $\mathrm{A} \S \mathrm{E}$ psychoacoustic test suite aims at assessing cochlear function in this way. Different tests have been developed within the A\$E platform, including a loudness scaling test to address intensity coding at the identification level, and phoneme detection, discrimination, and identification tests to address spectral coding. Within the European project DUAL PRO, a set of discrimination and identification tests have been developed (described in this and previous publications) to address temporal coding of the cochlea and, more specifically, to investigate low frequency coding. All these tests exist in two variants, one where the cue to make the distinction still contains spectral information above $300-400 \mathrm{~Hz}$ and another where this cue contains spectral information only below $300-400 \mathrm{~Hz}$. We speculate that the latter task can only be resolved by an underlying mechanism of phase locking, whereas the first task may be resolved by either phase locking or tonotopical coding (or a combination of both).

In this study, we investigated pitch perception in groups of hearing-impaired subjects suffering from a sensorineural hearing loss in the high-frequency range or in the lowfrequency range, and in a group of CI users. It was anticipated that a hearing loss in the low-frequency range would have a larger (negative) impact on pitch perception than a hearing loss in the high-frequency range.

Results in the groups of unaided hearing-impaired subjects confirmed our hypothesis: a sensorineural hearing loss in the high-frequency range with normal thresholds at low frequencies did yield somewhat higher JNDs than the hearing controls, but most of these subjects still fell within the normal range for most tests. A hearing loss in the low-frequency range, however, clearly affected the ability to perceive pitch, especially in the tests in which the subjects could only rely on low-frequency information, such as the DI test. This is in accordance with the results of Chung et al. [29], who claimed that patients with a Menières-like hearing loss have a decreased ability to make use of TFS cues, and thus are expected to show a decreased performance on perception tasks targeting these cues. Especially in the case of the DI test, it should be noted that the HI LF group demonstrated a large variability, indicating that some of these subjects were able to perform as well as hearing subjects. Although the reason for this variability among Menières-like patients is unclear, it shows that an audiological evaluation based solely on pure tone thresholds gives only limited information about cochlear function. Based on tonal audiometry, these patients would be treated as one group, namely as subjects suffering low-frequency hearing loss. But when this group of patients is examined using intonational tests, it appears that the group can be differentiated into subgroups of patients who still perform relatively well on low-frequency TFS coding and those who do not.

As expected, the CI subjects experienced great difficulty in performing intonational tests. Due to technical limitations, cochlear implants are not able to code lowfrequency information [36], resulting in only restricted information about pitch. This was especially clear for the DI test: as soon as the harmonics were left out, and the CI patients had to rely on low-frequency information (and thus phase-locking) only, their median JND rose from 16 $\mathrm{Hz}$ on the $\mathrm{HI}$ test to $139 \mathrm{~Hz}$ on the DI test. Most CI subjects did not yield a JND on the linguistic tests. Similar to the HI LF group, we found a very large variability in this CI group on all tests, suggesting that some CI subjects were able to perform within the normal range. The reason for this remains to be investigated. A possible effect of device type could not be investigated because of small sample sizes.

For all groups, the results demonstrated higher JNDs on the linguistic tests than on the synthetic tests. Performance differences between the two tests could be due to several factors. The linguistic stimuli differed from the synthetic ones in both type of content (tone complexes versus multiple syllables) and length (600 ms versus $886-1638 \mathrm{~ms})$. Longer stimuli are generally more suitable for speech pitch perception but put higher demands on auditory short term memory, which may have influenced performance. In addition, linguistic tests could be more difficult because prominence is normally conveyed not only by pitch but also by other cues such as syllable duration and intensity $[42,43]$. In these linguistic tests, however, the only cue available was the pitch dimension since syllable duration and intensity cues were normalised.

For all groups, we found that the filtered linguistic tests tended to be easier than the unfiltered ones. This could be because hearing out the pitch in unfiltered linguistic stimuli may be more difficult, as it is embedded in ongoing, but irrelevant, segmental changes in the acoustic signal such as formant structure. Taking out this considerable amount of linguistic, segmental information appeared to "simplify" the SI and WSP tests. The reverse was true for the synthetic tests: for all groups, the unfiltered HI test was easier than the filtered DI test. Indeed, in the case of purely synthetic stimuli without any segmental material, the absence of high-frequency information (i.e. the DI test) made the task more difficult.

As said earlier, we believe that these tests may allow better insight into cochlear functioning and this may be helpful in evaluating therapies. For instance, it might be expected that electro-acoustic stimulation (EAS) outperforms electric stimulation (CI) in terms of low frequency coding. EAS combines acoustic amplification of low frequencies by conventional hearing aid technology and electric amplification of the mid and high frequencies by cochlear implant technology. The EAS device is intended for hearing-impaired individuals with a profound deafness at high frequencies ( $>90 \mathrm{dBHL}$ hearing loss for frequencies above $1 \mathrm{kHz}$ ) and residual hearing at low frequencies. If the residual low frequency hearing in EAS candidates allows good low frequency TFS coding, it is expected that acoustic amplification may enhance the coding of TFS cues necessary for pitch perception. This might explain the added benefit of EAS in speech perception in noise and music perception in comparison to traditional CIs [44-48]. 


\section{Conclusion}

The perception of pitch is crucially dependent on low frequency temporal sound information. The prosodic modules of A\$E 2009 allow the clinical testing of this low frequency coding. Our results show that hearing-impaired listeners with low frequency hearing loss, as well as CI users, have great difficulty in perceiving pitch changes in both synthetic complex sounds and speech sounds. These tests can therefore be used to diagnose different subgroups of hearing-impaired subject who have the same audiometric thresholds but different low frequency coding. This approach may also allow us to measure possible improvements through new hearing rehabilitation strategies such as electro-acoustic stimulation.

\section{Acknowledgements}

This research was supported by the EU FP7-SME "Dual Pro: Dual electric-acoustic speech processor with linguistic assessment tools for deaf individuals with residual low frequency hearing". We thank Sien De Niel and Kristin Daemers for help in testing the subjects.

\section{References:}

1. Moore BC: An introduction to the psychology of hearing. $5^{\text {th }}$ ed. Bingley: Emerald, 2008

2. Gelfand SA: Essentials of Audiology. $3^{\text {rd }}$ ed. New York: Thieme Medical Publishers, 2009

3. Moore BC: The role of temporal fine structure processing in pitch perception, masking, and speech perception for normalhearing and hearing-impaired people. J Assoc Res Otolaryngol, 2008; 9: 399-406

4. Rosen S: Temporal information in speech: acoustic, auditory and linguistic aspects. Philos Trans R Soc Lond B Biol Sci, 1992; 336: 367-73

5. Moore BC: The role of temporal fine structure in normal and impaired hearing. In: Dau T, Buchholz JM, Harte JM, Christiansen TU (eds.), Auditory signal processing in hearing-impaired listeners. Centertryk A/S, 2008

6. Kale S, Heinz MG: Envelope coding in auditory nerve fibers following noise induced hearing loss. J Ass Res Otolaryng, 2010; 11: 657-73

7. Johnson DH: The relationship between spike rate and synchrony in responses of auditory-nerve fibers to single tones. J Acoust Soc Am, 1980; 68: 1115-22

8. Palmer AR, Russell IJ: Phase-locking in the cochlear nerve of the guinea-pig and its relation to the receptor potential of inner hair-cells. Hear Res, 1986; 24: 1-15

9. Baer T, Moore BC: Effects of spectral smearing on the intelligibility of sentences in noise. J Acoust Soc Am, 1993; 94: 1229-41

10. Smith ZM, Delgutte B, Oxenham AJ: Chimaeric sounds reveal dichotomies in auditory perception. Nature, 2002; 416: 87-90

11. Gilbert G, Lorenzi C: The ability of listeners to use recovered envelope cues from speech fine structure. J Acoust Soc Am, 2006; 119: 2438-44

12. Lorenzi C, Gilbert G, Carn H et al: Speech perception problems of the hearing impaired reflect inability to use temporal fine structure. Proc Natl Acad Sci USA, 2006; 103: 18866-69

13. Baer T, Moore BC: Effects of spectral smearing on the intelligibility of sentences in the presence of interfering speech. J Acoust Soc Am, 1994; 95: 2277-80

14. Fullgrabe $\mathrm{C}$, Berthommier F, Lorenzi C: Masking release for consonant features in temporally fluctuating background noise. Hear Res, 2006; 211: 74-84

15. Gnansia D, Jourdes V, Lorenzi C: Effect of masker modulation depth on speech masking release. Hear Res, 2008; 239: 60-68

16. Hopkins K, Moore BC, Stone MA: Effects of moderate cochlear hearing loss on the ability to benefit from temporal fine structure information in speech. J Acoust Soc Am, 2008; 123 : $1140-53$
17. Nelson PB, Jin SH, Carney AE, Nelson DA: Understanding speech in modulated interference: cochlear implant users and normal-hearing listeners. J Acoust Soc Am, 2003; 113: 961-68

18. Qin MK, Oxenham AJ: Effects of simulated cochlear-implant processing on speech reception in fluctuating maskers. J Acoust Soc Am, 2003; 114: 446-54

19. Stickney GS, Nie K, Zeng FG: Contribution of frequency modulation to speech recognition in noise. J Acoust Soc Am, 2005; 118: $2412-20$

20. Buss E, Hall JW III, Grose JH: Temporal fine-structure cues to speech and pure tone modulation in observers with sensorineural hearing loss. Ear Hear, 2004; 25: 242-50

21. Santurette S, Dau T: Binaural pitch perception in normal-hearing and hearing-impaired listeners. Hear Res, 2007; 223: 29-47

22. Duquesnoy AJ: Effect of a single interfering noise or speech source upon the binaural sentence intelligibility of aged persons. J Acoust Soc Am, 1983; 74: 739-43

23. Festen JM, Plomp R: Effects of fluctuating noise and interfering speech on the speech-reception threshold for impaired and normal hearing. J Acoust Soc Am, 1990; 88: 1725-36

24. Lorenzi C, Debruille L, Garnier S et al: Abnormal auditory temporal processing for frequencies where absolute thresholds are normal. J Acoust Soc Am, 2009; 125: 27-30

25. Horwitz AR, Dubno JR, Ahlstrom JB: Recognition of low-passfiltered consonants in noise with normal and impaired highfrequency hearing. J Acoust Soc Am, 2002; 111: 409-16

26. Turner CW, Souza PE, Forget LN: Use of temporal envelope cues in speech recognition by normal and hearing-impaired listeners. J Acoust Soc Am, 1995; 97: 2568-76

27. Bacon SP, Viemeister NF: Temporal modulation transfer functions in normal-hearing and hearing-impaired listeners. Audiology, 1985; 24: 117-34

28. Moore BC, Glasberg BR: Temporal modulation transfer functions obtained using sinusoidal carriers with normally hearing and hearing-impaired listeners. J Acoust Soc Am, 2001; 110: 1067-73

29. Chung BJ, Hall JW III, Buss E et al: Menière's disease: effects of glycerol on tasks involving temporal processing. Audiol Neurotol, 2004; 9: 115-24

30. Kuo Y-C, Rosen S, Faulkner A: Acoustic cues to tonal contrasts in Mandarin: implications for cochlear implantation. J Acoust Soc Am, 2008; 123: 2815-24

31. Savino M: Intonational cues to discourse structure in a regional variety of Italian. In: Gilles P, Peters J (eds.), Regional variation in intonation. Tübingen: Niemeyer, 2004

32. Swertz M, Collier R, Terken J: Prosodic predictors of discourse finality in spontaneous monologues. Speech Communication, 1994; 15: 79-90 
33. Van Heuven VJ, Haan J: Phonetic correlates of statement versus question intonation in Dutch. In: Botinis A (ed.), Intonation: Analysis, Modelling and Technology. Dordrecht/Boston/ London: Kluwer, 2000

34. Bachorowski JA, Owren M: Acoustic correlates of talker sex and individual talker identity are present in a short vowel segment produced in running speech. J Acoust Soc Am, 1999; 102: 1054-63

35. Gfeller K, Turner C, Oleson J et al: Accuracy of cochlear implant recipients on pitch perception, melody recognition, and speech reception in noise. Ear Hear, 2007; 28: 412-23

36. Chatterjee M, Peng S: Processing F0 with cochlear implants: modulation frequency discrimination and speech intonation recognition. Hear Res, 2008; 235: 143-56

37. Stickney GS, Assman PF, Chang J, Zeng FG: Effects of cochlear implant processing and fundamental frequency on the intelligibility of competing voices. J Acoust Soc Am, 2007; 122: 1069-78

38. Govaerts PJ, Daemers K, Yperman M et al: Auditory Speech Sounds Evaluation $\left(\mathrm{A} \$ \mathrm{E}^{\circledast}\right)$ : a new test to assess detection, discrimination and identification in hearing impairment. Cochlear Implants Int, 2006; 7: 97-106

39. Heeren W, Coene M, Vaerenberg B et al: Development of the $A \S E$ test battery for assessment of pitch perception in speech. Cochlear Implants Int, 2012 [in press]
40. Vaerenberg B, Pascu A, Del Bo L et al: Clinical assessment of pitch perception. Otol Neurotol, 2011; 32: 736-41

41. Levitt H: Transformed up-down methods in psychoacoustics. J Acoust Soc Am, 1971; 49: 467-77

42. Fry DB: Duration and intensity as physical correlates of linguistic stress. J Acoust Soc Am, 1955; 27: 765-68

43. Whalen $\mathrm{DH}, \mathrm{Xu} \mathrm{Y}$ : Information for Mandarin tones in the amplitude contour and in brief segments. Phonetica, 1992; 49: $25-47$

44. Skarzynski H, Lorens A, Piotrowska A: A new method of partial deafness treatment. Med Sci Monit, 2003; 9(4): CS20-24

45. Turner CW, Gantz BJ, Vidal C et al: Speech recognition in noise for cochlear implant listeners: benefits of residual acoustic hearing. J Acoust Soc Am, 2004; 115: 1729-35

46. Gantz BJ, Turner CW, Gfeller KE, Lowder MW: Preservation of hearing in cochlear implant surgery: advantages of combined electrical and acoustical speech processing. Laryngoscope, 2005; 115: 796-802

47. Dorman MF, Gifford RH, Spahr AJ, McKarns SA: The benefits of combining acoustic and electric stimulation for the recognition of speech, voice and melodies. Audiol \& Neurotol, 2008;13: 105-12

48. Brockmeier SJ, Peterreins M, Lorens A et al: Music perception in electric acoustic stimulation users as assessed by the Mu.S.I.C. test. Adv Otorhinolaryngol, 2010; 67: 70-80 